\title{
Efficacy of coronary fractional flow reserve using contrast medium compared to adenosine
}

\author{
Selim Topcu', Ibrahim Halil Tanboğa ${ }^{1}$, Enbiya Aksakal ${ }^{1}$, Uğur Aksu², Oktay Gulcu' ${ }^{1}$, Oğuzhan Birdal ${ }^{1}$, \\ Arif Arısoy ${ }^{1}$, Arzu Kalaycı ${ }^{3}$, Fatih Rifat Ulusoy ${ }^{4}$, Serdar Sevimli ${ }^{1}$ \\ ${ }^{1}$ Department of Cardiology, Faculty of Medicine, Atatürk University, Erzurum, Turkey \\ ${ }^{2}$ Department of Cardiology, Kars State Hospital, Kars, Turkey \\ ${ }^{3}$ Department of Cardiology, Kosuyolu Kartal Heart Training and Research Hospital, Istanbul, Turkey \\ ${ }^{4}$ Department of Cardiology, Yalova State Hospital, Yalova, Turkey
}

Adv Interv Cardiol 2016; 12, 3 (45): 212-216

DOI: 10.5114 /aic.2016.61641

\begin{abstract}
A b s tract
Introduction: Coronary fractional flow reserve (FFR) is recommended as the gold standard method in evaluating intermediate coronary stenoses. However, there are significant debates concerning the agents and the timing of the measurement.

Aim: To compare the contrast medium induced $\mathrm{Pd} / \mathrm{Pa}$ ratio (CMR) with the FFR.

Material and methods: We enrolled 28 consecutive patients with 34 intermediate lesions who underwent coronary FFR measurement by intracoronary (i.c.) adenosine. After baseline Pd/Pa was calculated, a single contrast medium (lomeron) injection of $6 \mathrm{ml}(3 \mathrm{ml} / \mathrm{s})$ was performed manually. Within $10 \mathrm{~s}$ after the contrast medium injection, the CMR was calculated. Bolus injection of i.c. adenosine was performed to induce maximal hyperemia (from $60 \mu \mathrm{g}$ to $600 \mu \mathrm{g}$ ), and when it was $\leq 0.80$, the intermediate lesion was considered as significant.

Results: After bolus i.c. adenosine, 12 lesions of 34 (35.3\%) were identified as significant. The CMR value was $0.86 \pm 0.06$ (range: 0.71-0.97). There were no significant differences between FFR and CMR values ( $p=0.108)$. A substantial positive correlation between adenosine and contrast values was detected (0.886 and $p<0.001)$. Good agreement in Bland-Altman analysis was revealed (mean bias was 0.027, 95\% confidence interval 0.038-0.092). Receiver operating characteristics curve analysis showed 90.9\% sensitivity and $91.7 \%$ specificity for a cut-off value of 0.85 for the CMR compared to FFR $(\leq 0.80)$.

Conclusions: Our study showed that measuring the CMR is a feasible method compared to FFR. The CMR may be used in situations where adenosine cannot be administered.
\end{abstract}

Key words: adenosine, fractional flow reserve, contrast medium.

\section{Introduction}

Coronary fractional flow reserve (FFR) is the gold standard in evaluating the hemodynamic significance of intermediate coronary lesions [1]. In many clinical studies FFR-guided percutaneous coronary intervention (PCI) has proven a positive effect on patient long-term outcomes $[2,3]$. Maximal hyperemia is essential to ensure FFR measurements; therefore intravenous (i.v.) adenosine infusion is accepted as a gold standard method [4]. However, the search for a different hyperemic agent began due to the fact that $i . v$. adenosine is expensive and has potential side effects. Intracoronary (i.c.) adenosine, papaverine, sodium nitroprusside and nicorandil have been tested as alternatives [5]. Intracoronary adenosine was accepted as an alternative method to i.v. adenosine [6, 7]. Recently, coronary hemodynamic assessment methods without a hyperemic agent, such as the instantaneous wave free ratio, have been studied widely. However, there is still controversy about the use of this method [1, 4]. Non-ionic contrast media are routinely used in coronary angiography. Hyperemic effects of these agents have long been known. Two encouraging studies demonstrated that measurement of the significance of intermediate stenoses was feasible by using contrast medium instead of adenosine $[8,9]$.

Aim

Our study aimed to compare contrast medium induced $\mathrm{Pd} / \mathrm{Pa}$ ratio (CMR) with the FFR in the evaluation

\section{Corresponding author:}

Selim Topcu, Department of Cardiology, Faculty of Medicine, Atatürk University, 25100 Erzurum, Turkey, phone: +90 442358427,

e-mail: selim.topcu01@gmail.com

Received: 6.02.2016, accepted: 26.04.2016. 
of hemodynamic significance of angiographically intermediate stenosis.

\section{Material and methods}

\section{Study population}

From September 2015 to December 2015, 28 consecutive patients with 34 angiographically intermediate stenoses who underwent FFR were enrolled.

All patients had $50-70 \%$ stenoses of at least one major epicardial artery by visual assessment. Exclusion criteria were: saphenous venous graft stenosis, recent ( $<7$ days) acute coronary syndrome, left main coronary stenosis, tandem lesions in epicardial artery, baseline Pd/ $\mathrm{Pa} \leq 0.80$ and absolute contraindications to adenosine. The study was approved by the local ethics committee and conformed to the Declaration of Helsinki on human research.

\section{Pressure measurements and study protocol}

All interventions were performed from the femoral artery. $100 \mathrm{IU} / \mathrm{kg}$ unfractionated heparin (UFH) and 0.1$0.2 \mu$ i.c. nitroglycerin (NTG) were injected and a 0.014" pressure wire (Volcano Corporation, San Diego, California) was calibrated, then it was nulled and introduced via a guiding catheter. Before passing the lesion both curves (aortic pressure and the wire pressure curve) were equalized. After that the wire was introduced distal to the stenosis and the baseline Pd/Pa was calculated (Pd: mean coronary pressure distal to coronary lesion, Pa: mean aortic pressure).

\section{Measurement of CMR}

After baseline $\mathrm{Pd} / \mathrm{Pa}$ was calculated, single contrast medium (Iomeron) injection of $6 \mathrm{ml}(3 \mathrm{ml} / \mathrm{s})$ was performed manually. Ten seconds after the contrast medium injection, $\mathrm{Pd} / \mathrm{Pa}$ was calculated. Afterwards, the guiding catheter was flushed with saline.

\section{Measurement of FFR}

Bolus injection of i.c. adenosine was performed to induce maximal hyperemia (from $60 \mu \mathrm{g}$ to $600 \mu \mathrm{g}$ ). Incremental boli of $i . c$. adenosine $(60 \mu \mathrm{g}, 300 \mu \mathrm{g}, 600 \mu \mathrm{g})$ were administered with each successive dose given at least $60 \mathrm{~s}$ apart from the previous one or after returning to baseline hemodynamic conditions. Each administration was performed in 5 to $10 \mathrm{~s}$ followed by a rapid flush of saline. The FFR $\leq 0.80$ was considered significant.

\section{Statistical analysis}

Continuous variables were expressed as mean \pm standard deviation, categorical variables were expressed as percentages. To test the distribution of continuous data, the Kolmogorov-Smirnov test was used. Statistical significance of the relationship between CMR and FFR was assessed by Student's t-test. The relationship between CMR and FFR was quantified with Pearson's correlation coefficient. Agreement between CMR and FFR was assessed by Bland-Altman plots and 95\% confidence intervals. Receiver operating characteristics (ROC) curve analysis was performed to determine the cut-off value for CMR in prediction of hemodynamically significant lesions determined by FFR. A $p$-value $<0.05$ was considered statistically significant. SPSS version 20.0 (SPSS Inc., Chicago, IL, USA) was used for statistical analysis.

\section{Results}

Twenty-eight patients with 34 intermediate coronary lesions were enrolled in this study (age: $63.4 \pm 12.8$; $79 \%$ were male). Main characteristics of the study population are summarized in Table I. Baseline $\mathrm{Pd} / \mathrm{Pa}$ was $0.92 \pm 0.04$ (range: $0.84-0.99$ ). The FFR was $0.83 \pm 0.07$ (range: 0.69-0.96). Twelve (35.3\%) lesions were significant (FFR $\leq 0.80)$. Of those 9 patients underwent $\mathrm{PCl}$ and three patients underwent CABG. Transient atrioventricular block was observed in 12 patients, and 18 patients experienced angina and/or dyspnea. The CMR was 0.86 \pm 0.06 (range: $0.71-0.97$ ) (Figure 1). According to baseline $\mathrm{Pd} / \mathrm{Pa}$, both adenosine and the contrast medium caused significant hyperemia and lowered hyperemic Pd/Pa values (FFR and CMR). There were no significant differences between FFR and CMR values ( $p=0.108)$. A substantial positive correlation between FFR and CMR was detected $(r=0.886$ and $p<0.001)$ (Figure 2).

Good agreement in Bland-Altman analysis was revealed (mean bias was $0.027,95 \%$ confidence interval $(\mathrm{Cl})$ -0.038 to 0.092 ) (Figure 3). In addition there was a significant correlation between $\mathrm{Pd} / \mathrm{Pa}$, FFR and CMR values $(r=0.777, p<0.001$ and $r=0.915, p<0.001$, respectively).

Table I. Baseline clinical and angiographic characteristics of study population

\begin{tabular}{lc} 
Parameter & Value \\
\hline Age, mean \pm SD & $63.4 \pm 12.8$ \\
\hline Sex-male (\%) & 79 \\
\hline Hypertension (\%) & 39 \\
\hline Diabetes mellitus (\%) & 61 \\
\hline Smoking (\%) & 46 \\
\hline Previous CAD (\%) & 32 \\
\hline Previous PCI (\%) & 62 \\
\hline Vessels (\%): & 24 \\
\hline LAD & 14 \\
\hline RCA &
\end{tabular}




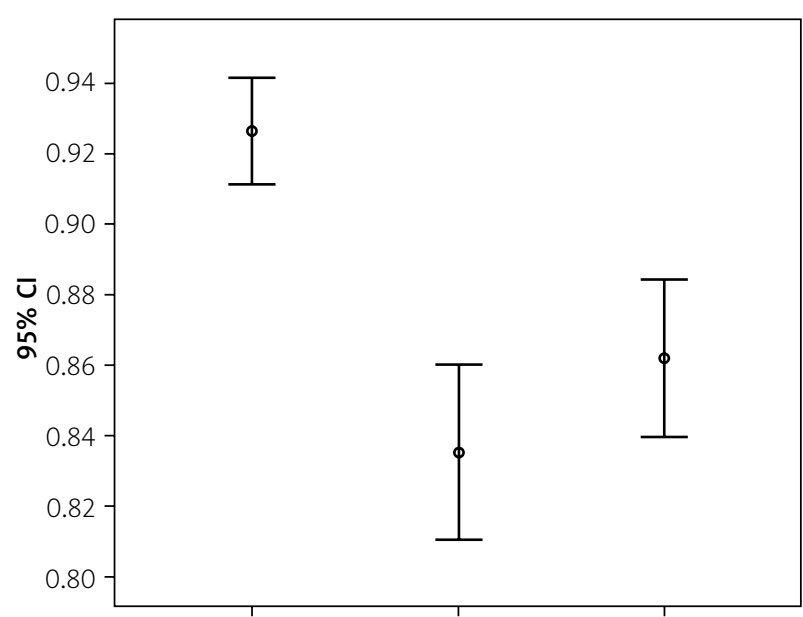

Baseline Pd/Pa Adenosine FFR Contrast FFR

Figure 1. Error plot for baseline $\mathrm{Pd} / \mathrm{Pa}$, adenosine FFR and contrast FFR

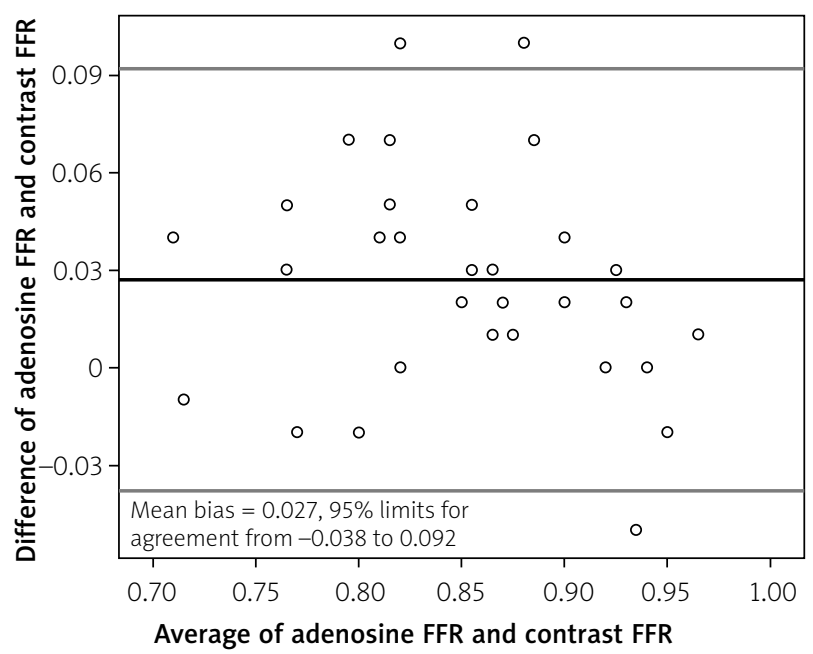

Figure 3. Bland-Altman plot showed a good agreement between contrast FFR and adenosine FFR

The ROC curve analysis showed $90.9 \%$ sensitivity and $91.7 \%$ specificity for a cut-off value of 0.85 for the CMR in comparison to FFR $\leq 0.80$ (Figure 4). The overall accuracy was $91.2 \%$, positive predictive value was $91.2 \%$, negative predictive value was $91.1 \%$ and Bayesian posttest probability was $91 \%$ (Figure 5 ). The false positive rate was $2 / 13$ and the false negative rate was $1 / 21$.

\section{Discussion}

Our study demonstrated that CMR measurements using contrast medium are feasible and represent a new index in the measurement of hemodynamically significant coronary stenoses as an alternative to adenosine. Using the cut-off value of 0.85 for the CMR could be

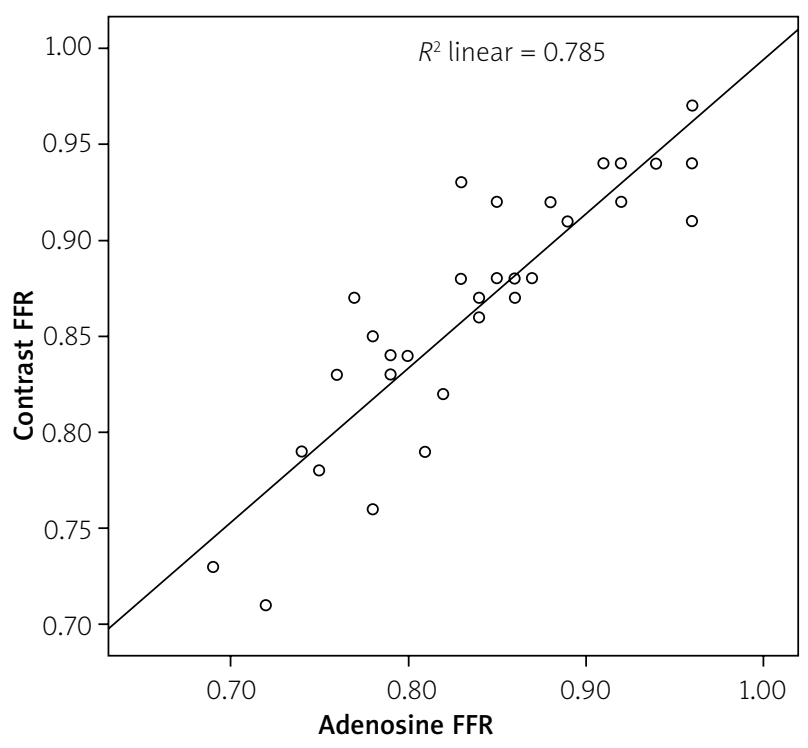

Figure 2. Correlation plot between adenosine and contrast FFR

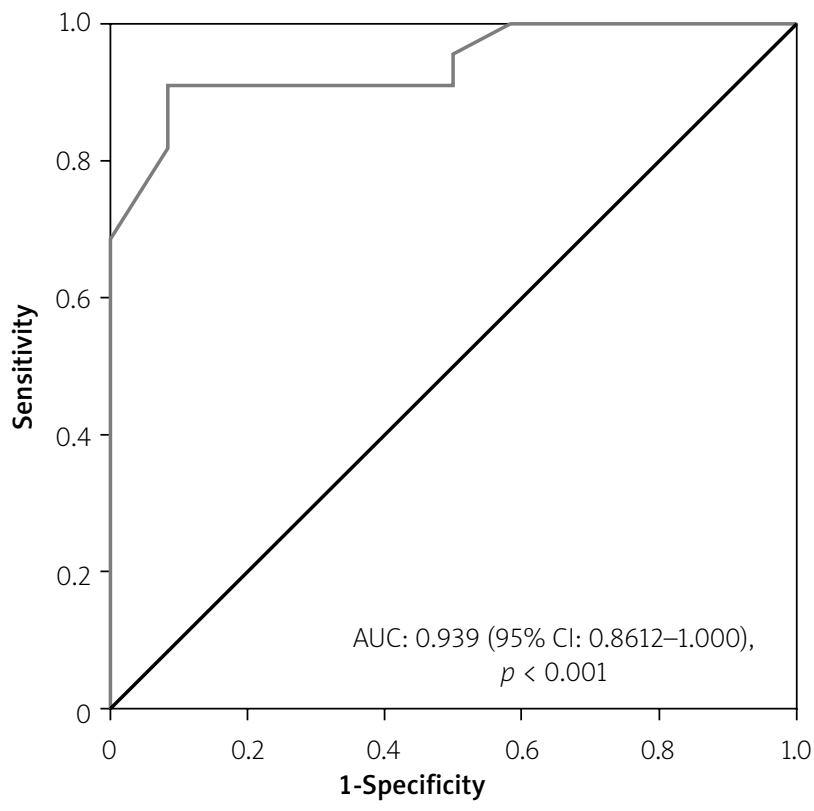

Figure 4. ROC curve analysis for contrast FFR in prediction of hemodynamically significant coronary lesion assessed by adenosine FFR

a viable option in patients who have a contraindication to the administration of adenosine. The FFR is regarded as the gold standard in the hemodynamic evaluation of intermediate coronary lesions [7, 10-12]. Long-term $\mathrm{CV}$ risk was found to be lower for FFR-guided $\mathrm{PCI}$ when compared to angiographically guided $\mathrm{PCl}[2,3]$. For FFR measurements maximal hyperemia induced by adenosine is mandatory $[4,6,13]$. Because of potential side effects and i.v. adenosine challenges (i.v. infusion, time consuming, etc.), the use of various alternative agents 
has been studied (i.c. adenosine, regadenoson, nitroprusside, etc.) [5, 14]. Furthermore, in order to overcome financial difficulties or side effects associated with the use of medications, a new adenosine-free index based on the measurement of the resting gradient called the instantaneous wave free ratio (iFR) was suggested [15]. However, there are still ongoing debates regarding the results of iFR studies.

Currently, there are many studies being conducted with the aim of finding a cheaper and easy-to-use method for the evaluation of hemodynamic significance of coronary stenoses comparable to FFR. One of them is the CMR $[5,14]$. It has been known for a long time that the contrast medium is a hyperemic agent [14]. Even though it was reported that the contrast medium causes only submaximal hyperemia [14], it has been determined recently that it causes effective enough hyperemia and could be used in the evaluation of intermediate coronary stenoses $[9,16]$. In the RINASCI study, a substantial correlation $(r=0.98)$ and good agreement (mean bias: $0.02,95 \% \mathrm{Cl}:-0.03$ to 0.07 ) were determined in the measurements of 102 intermediate lesions between FFR and the CMR [16]. Similarly, in the study by Spagnoli et al. a substantial correlation was determined $(r=0.90)$ [17]. The same was confirmed in our study. We determined a substantial correlation $(r=0.886)$ and good agreement (mean bias: 0.027, $95 \% \mathrm{Cl}:-0.038$ to 0.092 ) between the FFR and the CMR measurements. Besides contrast medium, iFR has emerged as an alternative method to FFR [15]. In the recent ADVISE study, a strong correlation (0.90) and a good agreement $(0.05 \pm 0.19)$ between iFR and FFR were established [18]. However, the agreement was lower than in our and RINASCI studies. In a comprehensive study Kanaji et al. (CMR, iFR and contrast iFR) determined $r=0.85$, mean bias: $0.016 \pm 0.055$ between CMR and FFR; $r=0.74$, mean bias: $0.072 \pm 0.064$ between $\mathrm{IFR}$ and FFR; and $r=0.93$, mean bias: $0.038 \pm 0.051$ between contrast iFR and FFR. In their study, contrast iFR had no superiority regarding the compliance with FFR, whereas the correlation was found to be stronger [9].

Our study had several limitations. The most important limitation was a low number of patients. Secondly, unlike other studies in the literature, we used i.c. adenosine instead of i.v. Thirdly, while determining the CMR, contrast medium was injected manually. Manual administration is more common in daily practice, which may be important in terms of demonstrating the effect of administering the contrast medium rather than being considered as a limitation. For the CMR to become a standard method in the evaluation of hemodynamic significance of coronary stenoses, the method should be standardized and validated with more comprehensive studies, measurement time should be evaluated (end-diastolic or mean), and more importantly, its relationship with the long-term clinical outcomes should be determined.

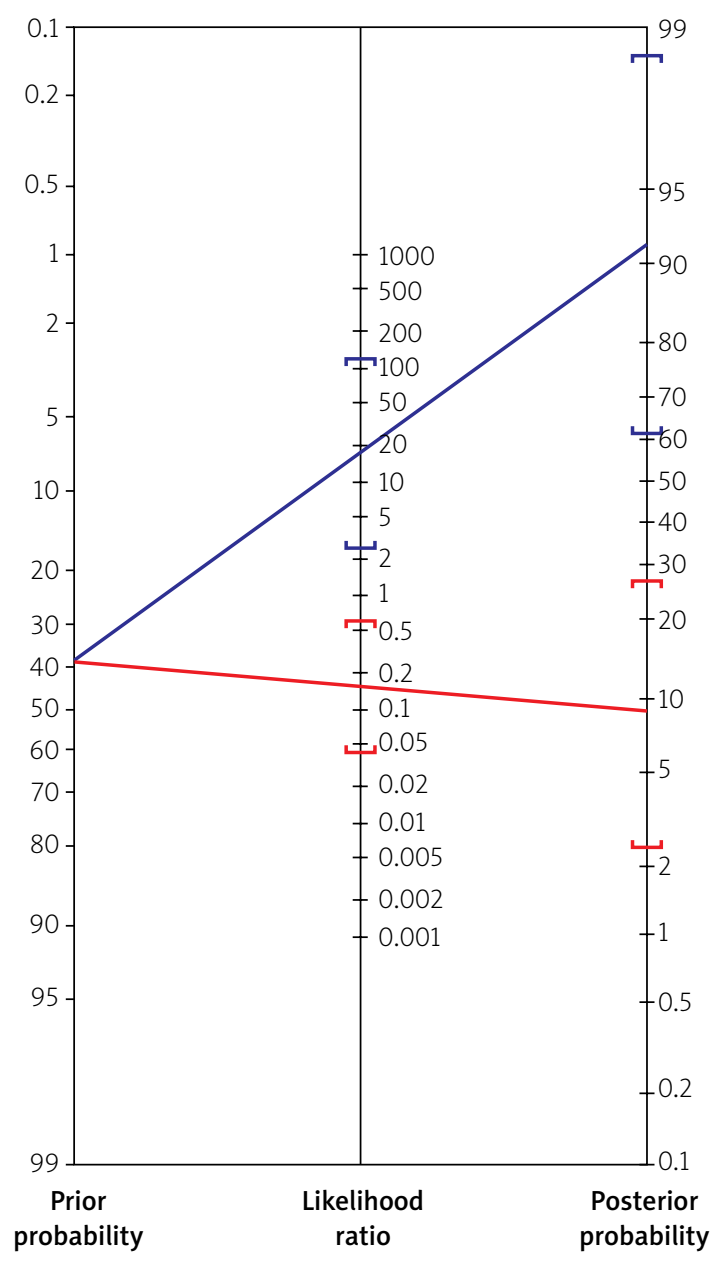

Figure 5. Bayesian nomogram (a straight line through the pretest probability of $38 \%$ and the LR+ of 17 yields a posttest probability of $91.2 \%$; a straight line through the pretest probability of $38 \%$ and the LR- of 0.16 yields a posttest probability of $8.8 \%$ )

\section{Conclusions}

Our study suggests that the CMR with manually administered contrast medium is feasible and that the CMR may be used in situations where the administration of adenosine is contraindicated.

\section{Conflict of interest}

The authors declare no conflict of interest.

\section{References}

1. Berry C, Corcoran D, Hennigan B, et al. Fractional flow reserve-guided management in stable coronary disease and acute myocardial infarction: recent developments. Eur Heart J 2015; 36: 3155-64.

2. De Bruyne B, Pijls NH, Kalesan B, et al. Fractional flow reserve-guided $\mathrm{PCl}$ versus medical therapy in stable coronary disease. N Engl J Med 2012; 367: 991-1001. 
3. Tonino PA, De Bruyne B, Pijls NH, et al. Fractional flow reserve versus angiography for guiding percutaneous coronary intervention. N Engl J Med 2009; 360: 213-24.

4. van de Hoef TP, Siebes M, Spaan JA, et al. Fundamentals in clinical coronary physiology: why coronary flow is more important than coronary pressure. Eur Heart J 2015; 36: 3312-9.

5. McGeoch RJ, Oldroyd KG. Pharmacological options for inducing maximal hyperaemia during studies of coronary physiology. Catheter Cardiovasc Interv 2008; 71: 198-204.

6. De Bruyne B, Pijls NH, Barbato E, et al. Intracoronary and intravenous adenosine 5'-triphosphate, adenosine, papaverine, and contrast medium to assess fractional flow reserve in humans. Circulation 2003; 107: 1877-83.

7. Groves EM, Seto AH, Kern MJ, et al. Invasive testing for coronary artery disease: FFR, IVUS, OCT, NIRS. Heart Fail Clin 2016; 12: 83-95.

8. Martin-Reyes R, de la Torre Hernandez JM, Franco-Pelaez J, et al. The use of the acute $\mathrm{Pd} / \mathrm{Pa}$ drop after intracoronary nitroglycerin infusion to rule out significant FFR: CANICA (Can intracoronary nitroglycerin predict fractional flow reserve without adenosine?) multicenter study. Catheter Cardiovasc Interv 2016; 87: 262-9.

9. Kanaji Y, Murai T, Lee T, et al. Efficacy of pressure parameters obtained during contrast medium-induced submaximal hyperemia in the functional assessment of intermediate coronary stenosis. Int J Cardiol 2016; 202: 207-13.

10. Naganuma T, Latib A, Costopoulos C, et al. The role of intravascular ultrasound and quantitative angiography in the functional assessment of intermediate coronary lesions: correlation with fractional flow reserve. Cardiovasc Revasc Med 2014; 15: 3-7.

11. Morris PD, van de Vosse FN, Lawford PV, et al. "Virtual” (computed) fractional flow reserve: current challenges and limitations. JACC Cardiovasc Interv 2015; 8: 1009-17.

12. Boden WE, O'Rourke RA, Teo KK, et al. Optimal medical therapy with or without $\mathrm{PCl}$ for stable coronary disease. N Engl J Med 2007; 356: 1503-16.

13. Bech GJ, De Bruyne B, Pijls NH, et al. Fractional flow reserve to determine the appropriateness of angioplasty in moderate coronary stenosis: a randomized trial. Circulation 2001; 103: 2928-34.

14. Tatineni S, Kern MJ, Deligonul U, et al. The effects of ionic and nonionic radiographic contrast media on coronary hyperemia in patients during coronary angiography. Am Heart J 1992; 123 : 621-7.

15. Berry C, van 't Veer M, Witt N, et al. VERIFY (VERification of Instantaneous Wave-Free Ratio and Fractional Flow Reserve for the Assessment of Coronary Artery Stenosis Severity in EverydaY Practice): a multicenter study in consecutive patients. J Am Coll Cardiol 2013; 61: 1421-7.

16. Leone AM, Scalone G, De Maria GL, et al. Efficacy of contrast medium induced $\mathrm{Pd} / \mathrm{Pa}$ ratio in predicting functional significance of intermediate coronary artery stenosis assessed by fractional flow reserve: insights from the RINASCI study. Eurolntervention 2015; 11: 421-7.

17. Spagnoli V, Amabile N, Dillinger JG, et al. Myocardial fractional flow reserve measurement using contrast media as a first-line assessment of coronary lesions in current practice. Can J Cardiol 2016; 32: 739-46.

18. Sen S, Escaned J, Malik IS, et al. Development and validation of a new adenosine-independent index of stenosis severity from coronary wave-intensity analysis: results of the ADVISE (ADenosine Vasodilator Independent Stenosis Evaluation) study. Am Coll Cardiol 2012; 59: 1392-402. 